\title{
Pengaruh Prenatal Care Yoga terhadap Pengurangan Keluhan Ketidaknyamanan Ibu Hamil Trimester III di Puskesmas Putri AyuKota Jambi
}

\author{
Gustina $^{1}$, Nurbaiti ${ }^{2}$ \\ ${ }^{1,2}$ Program Studi D III Kebidanan,STIkes Baiturrahim, Jambi \\ Email:gtina1870@gmail.com
}

Submitted :03 /04/2020

Accepted: $17 / 04 / 2020$

Published: 7/09/2020

\begin{abstract}
During pregnancy changes will occur in the entire body system of the mother both physically and psychologically, although physiological but if not understood by the mother and not treated will be able to make discomfort very disturbing during the process of pregnancy, childbirth and the puerperium, Prenatal Care Yoga is expected to help in dealing with discomfort during pregnancy, especially the third trimester of pregnancy Putri Ayu Health Center has provided pregnancy exercise services but has never given prenatal care yoga, due to the absence of trained staff at the Puskesmas, the researchers chose Puskesmas Putri Ayu as a research site. Intervene prenatal care yoga with quasi experimental one group pre-post-test design method. affordable population of 301 people visits K4 pregnant women to the Putri Ayu health center. he sample of purposive sampling was 32 people. The subject was carried out pre test and post test in the form discomfort questionnaire using a comparative scale of pain. Prenatal care yoga 4 times for 4 consecutive weeks Most of the third stage discomfort was pre-test, 21 (65.6\%), post-test to 15 (46.9) there was an effect of prenatal care yoga on reducing complaints of discomfort of third trimester pregnant women with a p-value <0,000 $195 \%$ CI).
\end{abstract}

Keywords: discomfort, pregnancy, yoga

\begin{abstract}
Abstrak
Selama kehamilan akan terjadi perubahaan-perubahan pada seluruh sistem tubuh ibu baik fisik maupuan psikologis, walaupun fisiologis tapi bila tidak dimengerti oleh ibu dan tidak ditangani akan bisa membuat ketidak nyamanan menjadi sangat mengganggu selama proses kehamilan, bersalin dan nifas.Prenatal Care Yoga diharapkan akan membantu dalam mengatasi ketidak nyamanan selama kehamilan terutama kehamilan trimester III. Puskesmas Putri Ayu telah memberikan pelayanan senam hamil tetapi belum pernah memberikan prenatal care yoga, dikarenakan belum adanya tenaga terlatih di Puskesmas tersebut, maka peneliti memilih Puskesmas Putri Ayu sebagai tempat penelitian. Melakukan intervensi prenatal care yoga dengan metoda quasi eksperimental one grup pre-post-test design. Populasi terjangkau 301 orang kunjungan K4 ibu hamil ke puskesmas Putri Ayu. Sampel purposive sampling sebanyak 32 orang. Subjek dilakukan pre test dan post test berupa kuesioner ketidaknyamanan menggunakan comparative scale nyeri. Prenatal care yoga 4 kali selama 4 minggu berturut-turut. Ketidaknyamanan kala III terbanyak pre-test yaitusakit pinggang21 (65,6\%), post-test menjadi $15(46,9)$ terdapat pengaruh prenatal care yoga terhadap pengurangan keluhan ketidaknyamanan ibu hamil trimester III di Puskesmas Putri Ayu dengan p-value $\leq 0,000$ (CI 95\%.
\end{abstract}

Kata kunci: kehamilan, ketidaknyamanan, yoga

\section{PENDAHULUAN}

Selama kehamilan akan terjadi perubahaan - perubahan pada seluruh sistem tubuh ibu baik fisik maupun psikologis, walaupun perubahan fisiologis tapi bila tidak dimengerti oleh ibu dan tidak ditangani akan bisa membuat ketidak nyamanan menjadi sangat mengganggu selama proses kehamilan, bersalin dan nifas.

Kesehatan Ibu selama kehamilan sampai menjelang persalinan tidak hanya dipengaruhi oleh baiknya nutrisi yang dikonsumsi Ibu selama kehamilan, melainkan dibutuhkan ketenangan pikiran dan tubuh yang sehat serta siap lahir dan 
bathin mempunyai peran yang penting dalam memudahkan proses kehamilan dan persalinan. Proses kehamilan yang nyaman tanpa keluhan fisik dan proses persalinan yang lancar dan mudah dapat didukung dengan memperhatikan 3 aspek utama dalam kehamilan yaitu

Prenatal Care Yoga diharapkan akan membantu dalam mengatasi ketidak nyamanan selama kehamilan terutama kehamilan trimester III. Membawa Ibu hamil ke dalam suasana kehamilan yang lebih tenang serta mempersiapkan tubuh fisik ibu hamil dengan lebih baik.Prenatal Gentle Yoga membantu ibu kembali menyadari dan mengenali tubuh fisiknya yang berubah selama kehamilan, dan membuat komunikasi dan bonding dengan bayi jauh lebih dekat (Yesie Aprilla, RYT, RPYT, 2018).Sesuai dengan penelitian Rafika, bahwa prenatal yoga efektif terhadap pengurangan keluhan fisik ibu hamil trimester III.sebesar 3.75; ( $\mathrm{p}=0,000<\alpha=0,05$ Tujuan Penelitian ini mengetahui pengaruh prenatal care yoga terhadap pengurangan keluhan ketidaknyaman ibu hamil trimester III

\section{METODE PENELITIAN}

Melakukan intervensi prenatal care yoga dengan metoda quasi eksperimental grup pre-post-test design. Populasi terjangkau 301 orang kunjungan K4 ibu hamil ke puskesmas Putri Ayu. Sampel purposive sampling sebanyak 32 orang. Subjek dilakukan Prenatal care yoga 4 kali selama 4 minggu berturut-turut, pre test dan post test berupa kuesioner ketidaknyamanan menggunakan comparative scale nyeri. Data dianalisis menggunakan teknik univariat dan bivariat.

\section{HASIL DAN PEMBAHASAN}

\section{Karakteristik responden}

Karakteristik responden pada penelitian ini terdiri dari usia, pendidikan, pekerjaan, gravida, usia kehamilan dan keluhan ketidaaknyamanan ibu hamil trimester III. Gambaran karakteristik responden dapat di lihat pada tabel di bawah ini:

\section{a. Umur Ibu}

Tabel1. Distribusi Responde Berdasarkan Umur Ibu di Puskesmas Putri Ayu Kota Jambi Tahun 2019

\begin{tabular}{cll}
\hline Umur Ibu (Tahun) & $f$ & \% \\
\hline$<20$ & 1 & 3.1 \\
$20-24$ & 10 & 31.2 \\
$25-29$ & 12 & 37.5 \\
$\geq 30$ & 9 & 28.1 \\
\hline Total & 32 & 100 \\
\hline
\end{tabular}

Berdasarkan tabel 1 diproleh data umur ibu yang terbanyak pada umur 25-29 tahun yaitu sebanyak 12 responden $(37,5 \%)$.

b. Pendidikan

Tabel2.Distribusi Responden Berdasarkan Pendidikan Ibu di PuskesmasPutri Ayu Kota Jambi Tahun 2019

\begin{tabular}{lll}
\hline Pendidikan & $f$ & \% \\
\hline SD/Sederajat & 1 & 3.1 \\
SMP/Sederajat & 9 & 28.1 \\
SMA/Sederajat & 17 & 53.1 \\
Perguruan Tinggi & 5 & 15.6 \\
\hline Total & 32 & 100 \\
\hline
\end{tabular}

Berdasarkan table 2 diproleh hasil data pendidikan ibu yang terbanyak berpendidikan SMA/Sederajat yaitu sebanyak 17 responden $(53,1 \%)$.

\section{c. Pekerjaan}

Tabel 3. Distribusi Responden Berdasarkan Pekerjaan Ibu di Puskesmas Putri Ayu Kota Jambi Tahun 2019

\begin{tabular}{lll}
\hline Pekerjaan & $F$ & \% \\
\hline Ibu Ramah Tangga & 27 & 84.4 \\
Swasta & 4 & 12.5 \\
ASN & 1 & 3.1 \\
\hline Total & 32 & 100 \\
\hline
\end{tabular}

Berdasarkan tabel 3. diproleh data pekerjaan ibu yang terbanyak adalah ibu rumah tangga yaitu sebnayak 27 responden $(84,4 \%)$.

\section{d. Gravida}


Tabel 4. Distribusi Responden Berdasarkan Gravida Ibu di Puskesmas Putri Ayu Kota Jambi Tahun 2019

\begin{tabular}{lll}
\hline Gravida & $F$ & $\mathbf{\%}$ \\
\hline $1-2$ & 23 & 71.9 \\
$3-4$ & 7 & 21.9 \\
$\geq 5$ & 2 & 6.2 \\
\hline Total & 32 & 100 \\
\hline
\end{tabular}

Berdasarkan tabel 5.4. diperoleh hasil data Gravida ibu terbanyak 1-2 yaitu sebanyak 23 responden $(71,9 \%)$.

\section{e. Usia kehamilan}

Tabel 5. Distribusi Responden Berdasarkan usia kehamilan Ibu di Puskesmas Putri Ayu Kota Jambi Tahun 2019

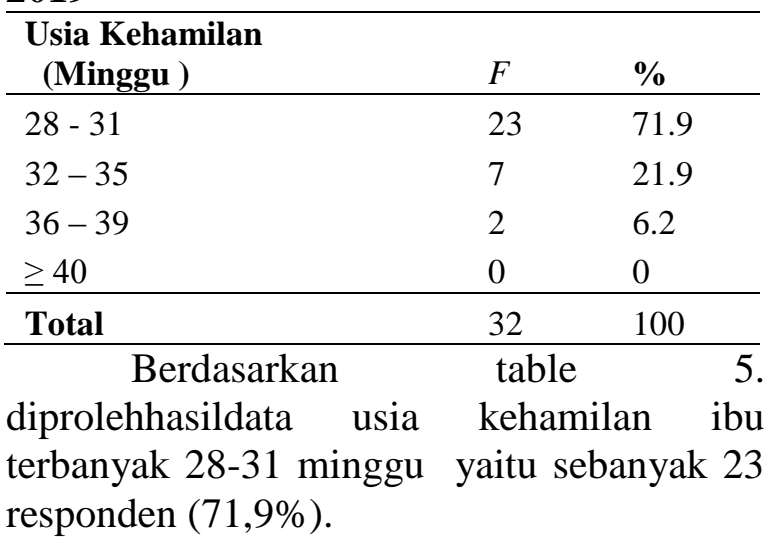

\section{Analisis Univariat}

Tabel 6. Distribusi Responden Berdasarkan keluhan fisik Ibu hamil trimester III pre-test dan Post-test dilakukan pelatihan prenatal care yoga di Puskesmas Putri Ayu Kota Jambi Tahun 2019

\begin{tabular}{|c|c|c|c|c|}
\hline \multirow[t]{2}{*}{ Ketidaknyamanan } & \multicolumn{2}{|c|}{ Pre-test } & \multicolumn{2}{|c|}{ Post-test } \\
\hline & $f$ & $\%$ & $F$ & $\%$ \\
\hline Sakit Pinggang & 21 & 65.6 & 15 & 46.9 \\
\hline Sakit tidak teratur & & & & \\
\hline $\begin{array}{l}\text { bila duduk dan } \\
\text { istirahat }\end{array}$ & 5 & 15.6 & 4 & 12.5 \\
\hline $\begin{array}{l}\text { Terasa tekanan pada } \\
\text { perut bagian bawah }\end{array}$ & 0 & 0 & 0 & 0 \\
\hline $\begin{array}{l}\text { Varises pada tungkai } \\
\text { bagian bawah }\end{array}$ & 2 & 6.3 & 2 & 6.3 \\
\hline $\begin{array}{l}\text { Merasa susah } \\
\text { bernafas }\end{array}$ & 1 & 3.1 & 1 & 3.1 \\
\hline Sering buang air & 3 & 9.4 & 3 & 9.4 \\
\hline Keluhan lain & 0 & 0 & 0 & 0 \\
\hline
\end{tabular}

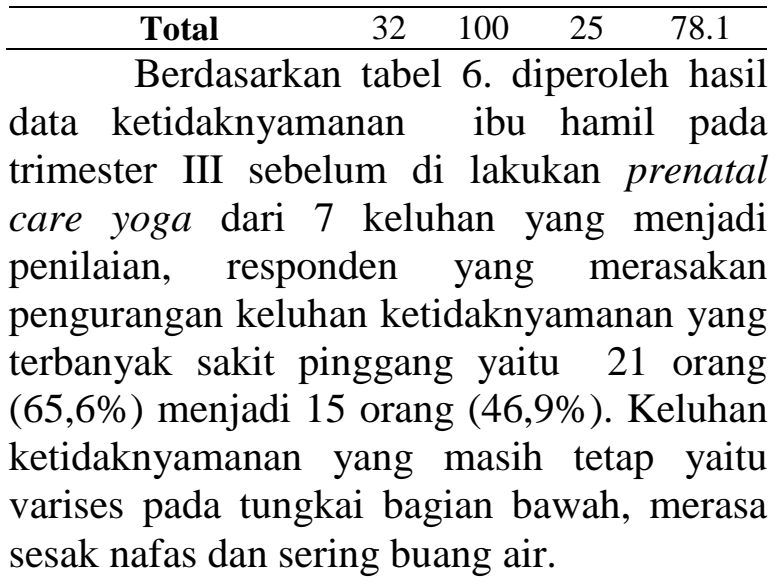

Tabel.7.Distribusi frekuensi pre-test ketidaknyaman Ibu hamil Trimester III di Puskesmas Putri Ayu Kota Jambi Tahun 2019

\begin{tabular}{ccc}
\hline & \multicolumn{2}{c}{ Kelompok } \\
\cline { 2 - 3 } Ketidaknyaman & $\begin{array}{c}\text { Frekuensi } \\
(\mathbf{n = 3 2})\end{array}$ & $\begin{array}{c}\text { Presentasi } \\
(\mathbf{\%}) \\
(\mathbf{n = 3 2})\end{array}$ \\
\hline Nyeri Ringan & 2 & 6,3 \\
Nyeri Sedang & 25 & 78,1 \\
Nyeri Berat & 5 & 15,2 \\
\hline \multicolumn{3}{c}{ Berdasarkan table. 7. di proleh hasil } \\
data ketidaknyaman sebelum di lakukan \\
prenatal care yoga yang terbanyak yaitu \\
nyeri sedang 25 responden $(78,1 \%)$.
\end{tabular}

Tabel 8. Distribusi frekuensi post-test ketidaknyaman Ibu hamil Trimester III diPuskesmas Putri Ayu Kota Jambi Tahun 2019

\begin{tabular}{ccc}
\hline & \multicolumn{2}{c}{ Kelompok } \\
\cline { 2 - 3 } Ketidaknyamanan & $\begin{array}{c}\text { Frekuensi } \\
(\mathbf{n = 3 2})\end{array}$ & $\begin{array}{c}\text { Presentasi } \\
(\mathbf{\%}) \\
(\mathbf{n = 3 2})\end{array}$ \\
\hline Nyeri Ringan & 26 & 83,1 \\
Nyeri Sedang & 4 & 12,5 \\
Nyeri Berat & 2 & 6,3 \\
\hline Berdasarkan tabek 8. di proleh hasil
\end{tabular}
data ketidaknyaman sesudah di lakukan prenatal care yoga yang terbanyak yaitu nyeri ringan 26 responden $(83,1 \%)$.

\section{Analisis Bivariat}

Pengaruh prenatal care yoga terdahap pengurangan keluhan ketidaknyamanan pada ibu hamil trimester III di Puskesmas Putri Ayu Kota Jambi Tahun 2019. 
Table. 9. Pengaruh prenatal care yoga terhadap keluhan ketidaknyamanan pada kehamilan trimester III di Puskesmas Putri Ayu Kota Jambi Tahun 2019

\begin{tabular}{cccc}
\hline \multirow{2}{*}{$\begin{array}{c}\text { Ketidakny } \\
\text { amanan }\end{array}$} & \multicolumn{2}{c}{ Kelompok } & \\
\cline { 2 - 3 } & $\begin{array}{c}\text { Pre } \\
(\mathbf{n}=32)\end{array}$ & $\begin{array}{c}\text { Post } \\
(\mathbf{n}=32)\end{array}$ & \\
\hline $\mathrm{x}(\mathrm{SD})$ & $6,14(1,417)$ & $3,54(1,776)$ & $<0,000^{*}$ \\
minimum & $4(5,81)$ & $1(6,46)$ & \\
maxsimum & $1(3,13)$ & $7(3,95)$ & \\
\hline
\end{tabular}

Berdasarkan tabel 9. di proleh hasil bahwa responden yang mengalami ketidaknyamaan pada saat pre-test sebelum di lakukan latihan prenatal care yoga yaitu $6,14(1,417)$ sedangkan ketidaknyamanan yang di alami responden setelah di lakukan prenatal care yoga pada saat post-test yaitu 3,54 (1,776) dan terdapat pengaruh yang signifikan antara prenatal care yoga terhadap pengurangan keluhan ketidaknyamanan pada kehamilan trimester III yaitu $p$ - value $\leq$ 0,000 (CI 95\%).

Hasil penelitian yang telah dilakukan sejalan dengan penelitian oleh Rafika tahun 2017 tentang Efektifitas Prenatal Yoga Terhadap Pengurangan Keluhan Fisik pada ibu Hamil Trimester III di Wilayah Kerja Puskesmas Komunji Kota Palu dengan jenis penelitian Quasi Eksperimen pendekatan Non Equivalent Control Group terhadap 16 kelompok interfensi dan 16 kelompok kontrol. Hasil penelitian menunjukkan bahwa hasil perbedaanselisih nilai rata-rata keluhan fisik kelompok kontrol dan kelompok intervensi sebesar 3.75; $(p=0.000<\alpha=0,05$, hasil ini terdapat perbedaan signifikan nilai rata-rata keluhan fisik responden antara kelompok kontrol dan kelompok intervensi.

Kesehatan Ibu selama kehamilan sampai menjelang persalinan tidak hanya dipengaruhi oleh baiknya nutrisi yang dikonsumsi ibu selama kehamilan, melainkan dibutuhkan ketenangan pikiran dan tubuh yang sehat serta siap lahir dan bathin mempunyai peran yang penting dalam memudahkan proses kehamilan dan persalinan. Proses kehamilan yang nyaman tanpa keluhan fisik dan proses persalinan yang lancar dan mudah dapat didukung dengan memperhatikan 3 aspek utama dalam kehamilan yaitu Keseimbangan (Rahim, otot dan panggul), Gravitasi dan Gerakan. (Yesie Aprilla, RYT, RPYT, 2018 ).

Pengaruh yoga antenatal telah dibuktikan juga melalui penelitian yang dilakukan oleh Devi Mediarti dkk terhadap Pengaruh Yoga Antenatal Terhadap Pengurangan Keluhan Ibu Hamil Trimester III dengan menggunakan quasi eksperimen pre test and post test one group dengan jumlah responden 25. Hasil uji statistik didapatkan nilai $\mathrm{p}=0,005$ disimpulkan ada perbedaan yang signifikan antara keluhan ibu hamil sebelum dilakukan yoga antenatal dan setelah dilakukan yoga antenatal. (Yesie Aprilla, RYT, RPYT, 2018)

Ketidaknyamanan pada kehamilan trimester III dengan usia kehamilan 28 - > 40 minggu, terjadinya karena perubahan fisik terutama pada berat badan, akibat pembesaran uterus dan sendi panggul sedikit mengendor menyebabkan ibu sering kali mengalami nyeri pinggang. (Prof. Peter Abraham, 2010)

Ketidaknyamanan merupakan suatu perasaan yang kurang ataupun yang tidak menyenangkan bagi kondisi fisik ataupun mental pada ibu hamil.kehamilan merupakan proses alamiah pada wanita yang akan menimbulkan berbagai perubahan dan menyebabkan rasa tidak nyaman,( Varney,1997 dan Prawirohardjo, 2002)

Gangguan ketidaknyamanan selama hamil dapat dipengaruhi oleh faktor fisik terkait perubahan anatomi, dan faktor psikologis.Pada umumnya gangguan ini bersifat fisiologis, namun dapat berubah menjadi patologis apabila tidak diatasi dengan tepat.Diagnosis yang tepat terkait gangguan ketidaknyamanan kehamilan dan penyebabnya penting dilakukan untuk penatalaksanaan yang tepat. Masing-masing wanita dapat diberikan treatment yang berbeda dengan kasus yang sama, untuk itu dibutuhkan pengetahuan dan pemahaman yang menyeluruh dari bidan agar dapat membantu ibu dalam mengatasi gangguan 
dan ketidaknyamanan selama kehamilan. (Varney, Kriebs, Gegor. 2002).

Banyak penemuan para ahli bahkan sudah berlangsung lama, bahwa seorang ibu yang sedang hamil akan dapat melewati kehamilannya dengan mudah bahkan sampai tahap melahirkan salah satunya yaitu dengan melakukan senam hamil. Banyak gerakan dalam senam hamil yang akan dapat meringankan beban ibu untuk menjalani kehamilannya dengan mudah hingga waktu persalinan. Senam hamil merupakan latihan rileksasi yang dilakukan oleh ibu hamil sejak usai kehamilan 28 minggu sampai masa kelahiran dan merupakan salah satu kegiatan dalam pelayanan selama kehamilan ( prenatal care). (A. Poppy, 2010).

Perlu disadari oleh ibu hamil, bahwa senam hamil adalah suatu bentuk latihan guna memperkuat dan mempertahnkan elastis dinding perut, ligament-ligament, otot-otot dasar panggul yang berhubungan dengan proses persalinan. Senam hamil sangat penting bagi ibu untuk tetap mendapatkan tubuh yang sehat dan bugar, salah satu bentuk senam hamil sesuai dengan penelitian prenatal care yoga pada ibu hamil trimester III. A. Poppy, 2010).

Yoga prenatal adalah sebuah ilmu yang menjelaskan kaitan antara fisik, mental, dan spiritual manusia untuk mencapai kesehatan yang menyeluruh. Melakukan latihan yoga pada saat hamil, akan mempersiapkan tubuh maupun pikiran untuk siap dan tegar menghadapi masa persalinan. Yoga merupakan seni olah tubuh dan pernafasan yang berasal dari India. Yoga dapat membentuk postur tubuh, membantu menjadi rileks, Mengurangi dan menghilangkan keluhan-keluhan yang dirasakan selama masa kehamilan dan menyeimbangkan dan menstabilkan tubuh pada ibu hamil

Latihan pernafasan dalam prenatal care yoga adalah latihan merelaksasikan seluruh tubuh yang sangat baik untuk mengendalikan dan mengatur pernafasan. Latihan pernafasan ini dapat menenangkan, menguatkan dan mengembalikan sistem respirasi dan sistem saraf ke posisi dan fungsi yang tepat.Selain itu latihan pernafasan juga dapat meningkatkan kapasitas dan elastis paru-paru.Latihan ini memberikan efek menenangkan alam pikiran dan perasaan. (Yesie Aprilla, RYT, RPYT, 2018)

Dari bahasan di atas menurut peneliti bahwa di dapatkan hasil, terjadi penurunan ketidaknyamanan berupa nyeri sedang ke nyeri ringan sehingga ibu hamil merasakan kenyamanan pada saat kehamilan trimester III.Setelah di lakukan pelatihan prenatal care yoga di harapkan ibu hamil dapat melakukan prenatal care yoga untuk mengatasi ketidaknyaman pada kehamilan trimester III.

\section{SIMPULAN}

Hasil penelitian disimpulkan Umur ibu rentang 25-29 tahun yaitu sebanyak 12 responden $(37,5 \%)$, sebagian besar pendidikan ibu SMA/Sederajat yaitu sebanyak 17 responden $(53,1 \%)$, sebagian besar pekerjaan ibu adalah ibu rumah tangga yaitu sebnayak 27 responden $(84,4 \%)$, sebagian besar Gravida ibu 1-2 yaitu sebanyak 23 responden $(71,9 \%)$, sebagian besar usia kehamilan ibu 28-31 minggu yaitu sebanyak 23 responden (71,9\%). Sebelum dilakukan pelatihan prenatal care yoga sebagian besar ketidaknyaman ibu sakit pinggang yaitu 21 orang $(65,6 \%)$. Setelah di lakukan pelatihan prenatal care yoga responden merasakan pengurangan pada ketidaknyamanan yang berjumlah 15 orang $(46,9 \%)$. Berdasarkan hasil uji statistik maka di dapat nilai $p-$ value $\leq 0,000$ (CI 95\%) maka terdapat pengaruh prenatal care yoga dengan pengurangan ketidaknyamanan pada ibu hamil trimester III di Puskesmas Putri Ayu Kota Jambi tahun 2019.

\section{DAFTAR PUSTAKA}

Asrinah dkk. 2010. Konsep kebidanan. Yogyakarta. Graha ilmu

Astuti Puji. 2012. Asuhan kebidanan masa kehamilan. Yogyakarta. Graha ilmu 
Bobak, Lowdermilk, Jensen, 2004, Buku Ajar Keperawatan Maternitas / Maternity Nursing. Alih Bahasa Maria A. Wijayanti. Peter I. Anugerah, edisi 4. Jakarta : EGC

Jurnal Kedokteran Dan Kesehatan, Volume 1, NO. 1, OKTOBER $2014:$ 47-53 Devi. Pengaruh Yoga Antenatal Terhadap Pengurangan Keluhan Ibu Hamil Trimester III di Wilayah Kerja Puskesmas

Jurnal Kesehatan Volume 9, Nomor 1, April 2018 ISSN 2086-7751 (Print), ISSN 2548-5695 (Online) http://ejurnal.poltekkestjk.ac.id/index.php/JK.Efektivitas Prenatal Yoga terhadap Pengurangan Keluhan Fisik pada Ibu Hamil Trimester III.

Notoadmodjo, S. 2010. IlmuPerilaku Kesehatan. PT Rineka Cipta. Jakarta.

Notoadmodjo, S. 2010. Metodologi Penelitian Kesehatan. Rineka Cipta. Jakarta

Notoatmodjo,Soekidjo, 2012. Promosi Kesehatan dan Ilmu Perilaku. PT Rineka Cipta. Jakarta.

Poppy, 2010. Serba - Serbi Senam Hamil, Yogyakarta. Intan Media.

Prof. Peter Abraham, alih bahasa Dr. Victor Setyadi, 2010 Panduan Kesehatan Dalam Kehamilan. Karisma Publisshing Group.

Rubertsson, C., Hellström, J., Cross, M. \& Sydsjö, G. (2014) Anxiety in early pregnancy: prevalence and contributing factors. Arch Womens Ment Health, 17 (3): 221-8.

Tim Trainner Prenatal Gentle Yoga (2016).Modul prenatal gentle Yoga. Kristara.

Ummi (2010). Asuhan kebidanan pada kehamilan fisiologis. Jakarta: Salemba Medika

Varney, H., Kriebs, J. M. \& Gegor, C. L. (2010) Varney's midwifery. Fourth edition. Jakarta: E
Varney, Kriebs, Gegor. 2002. Buku Ajar Asuhan Kebidanan, Edisi 4, Volume 1. EGC, Jakarta.

Varney. 1997. Varney's Midwifery, $3^{\text {rd }}$ Edition. Jones and Bartlett Publishers, London UK.

Walsh (2008). Midwifery :community-based care during the childbearing year.wilda eka handayani. Penerjemah (2008). Buku ajar kebidanan komunitas. Jakarta : EGC. 